\title{
Modeling and Simulation on Securing of Software Defined Network Overlays
}

\author{
Tomonobu Sato \\ Services Division, Hitachi ICT Business Services, Ltd., Tokyo, Japan \\ Email address: \\ tomonobu.sato.dm@hitachi.com

\section{To cite this article:} \\ Tomonobu Sato. Modeling and Simulation on Securing of Software Defined Network Overlays. International Journal of Intelligent \\ Information Systems. Special Issue: Securing of Software Defined Network Overlays. Vol. 8, No. 4, 2019, pp. 65-76. \\ doi: $10.11648 /$ j.ijiis.20190804.11
}

Received: July 15, 2019; Accepted: September 17, 2019; Published: October 30, 2019

\begin{abstract}
Security is one of the key technologies with which DX (Digital Transformation) supported. A sent data was sometimes noise for this nonlinear programming technique to have the restrictions which won't be more than 1 for the value of the amplified bit, without the most suitable functions can be found. It wasn't possible to build the large-scale network of which high security including authentication is requested. The same problem generated the algorithm which does a weighting of each antenna it became stable, and to secure high-speed transmission of a time zone cord at a multiple-input multiple-out (MIMO) channel by the Wireless environment equally. The purpose of this system is here to achieve to develop the technology for which security is secured by also utilizing the algorithm which will improve the algorithm which selects the filtering technique and the filtering which are the multiplex technology when a network transmits at high speed, and select the filtering later for a weighting of each antenna by time zone coding at the MIMO channel which is high-speed transmission technology by the wireless society and build the large-scale network environment that advantage convenience guaranteed high security highly freely and easily.
\end{abstract}

Keywords: Securing Network, Software Defined Network Overlays, MIMO

\section{Introduction}

This paper is concerned with network access management technology using filtering technique and the technology which estimates that the access management give prior evaluation.

Such as coding data, establishing a fire wall and doing garble prevention of the data which sends and receives a network by a bond to secure security of a network, it's the mainstream to put a security measure into effect by establishing software according to the network environment separately. Therefore, advantage convenience was high by conventional technology, and it was difficult to build the network environment that high security was guaranteed easily freely.

The purpose of this paper is here to achieve to develop the technology for which security is secured by also utilizing the algorithm which will improve the algorithm which selects the coding at the MIMO channel which is high-speed transmission technology by the wireless society and build the large-scale network environment that advantage convenience guaranteed high security highly freely and easily. [1-20] Filtering technique and the filtering which are the multiplex technology when a network transmits at high speed, and select the filtering later for a weighting of each antenna by time zone coding at the MIMO channel which is high-speed transmission technology by the wireless society and build the large-scale network environment that advantage convenience guaranteed high security highly freely and easily. [21-23]

\section{Reflection}

It's explained in detail based on a drawing about the implementation form of this research in the following.

Figure 1 is the illustrative embodiment network access management system configuration diagram.

Figure 2 is the illustrative embodiment network access management system function hierarchy diagram. 


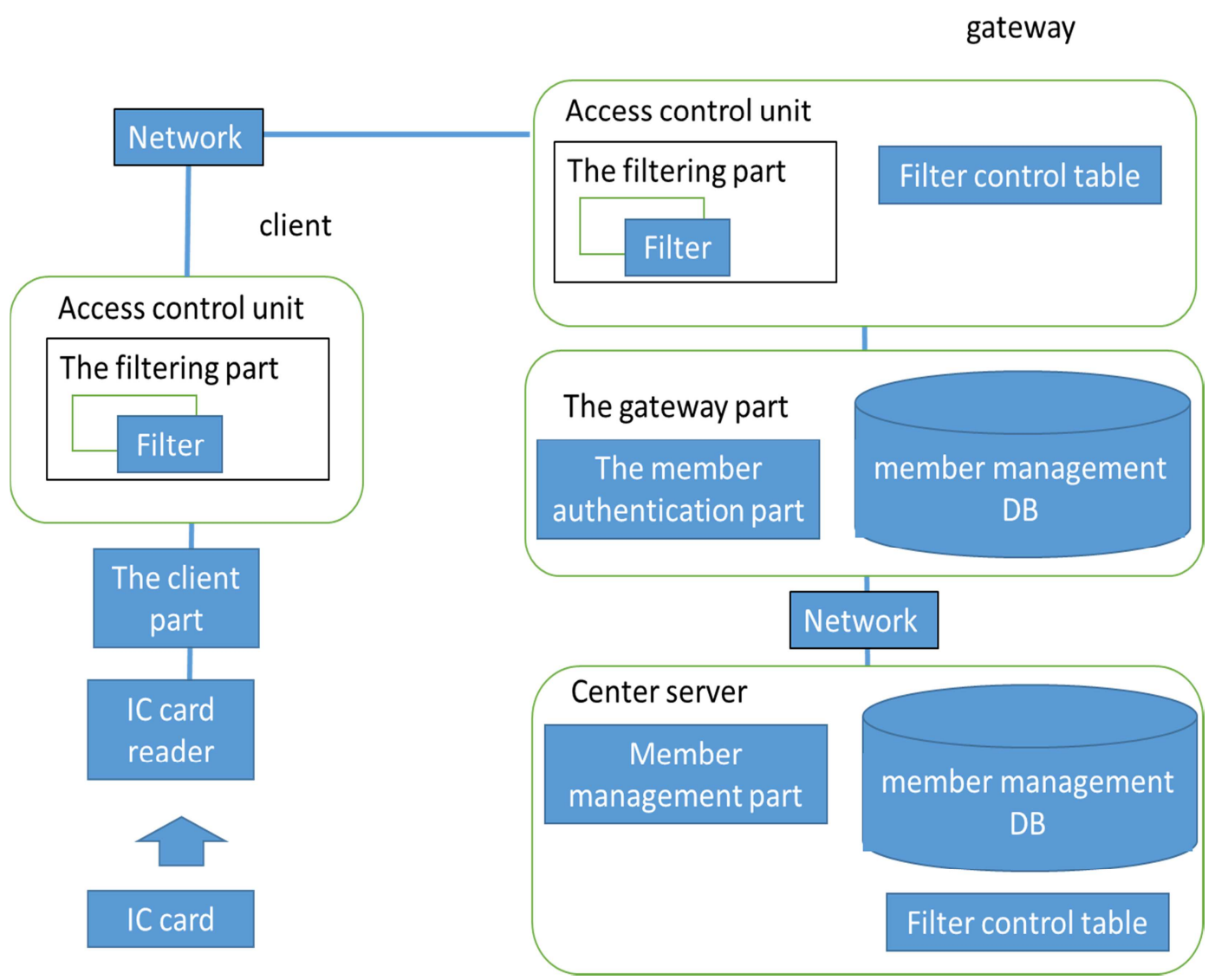

Figure 1. Network access management system configuration diagram.

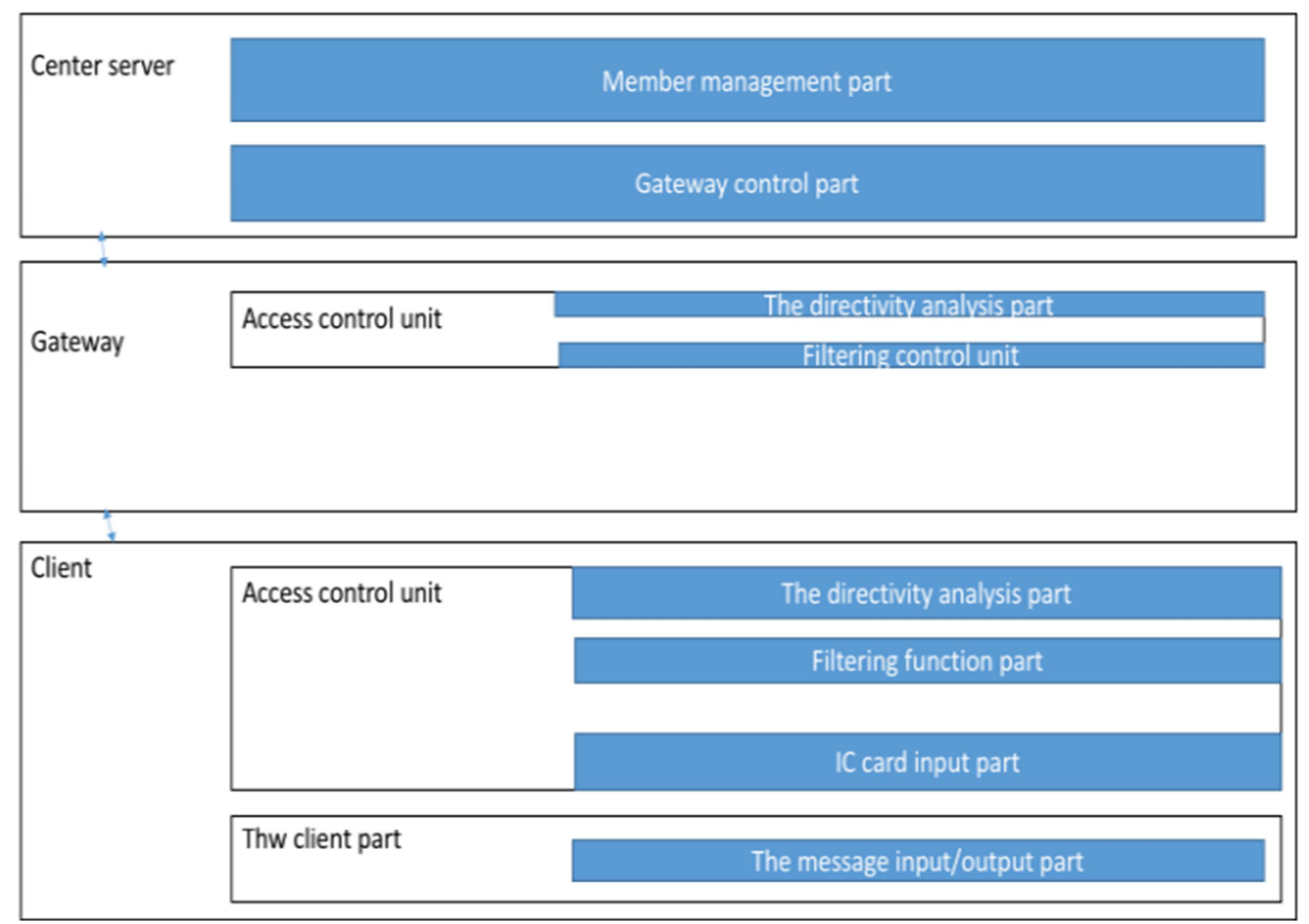

Figure 2. The network access management system function hierarchy diagram. 
Figure 3 is the illustrative embodiment Filter management table data configuration diagram.

Figure 4 is the illustrative embodiment the gateway part members' data DB data configuration diagram.

Figure 5 is the illustrative embodiment IC card data configuration diagram.

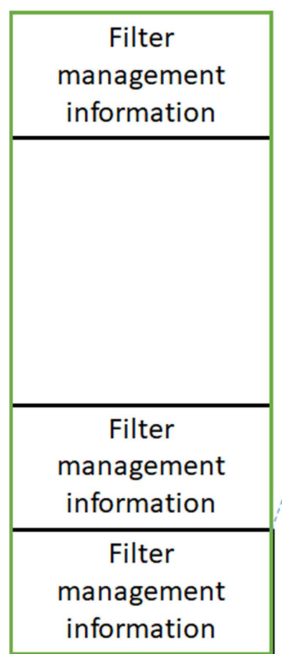

\begin{tabular}{|c|}
\hline $\begin{array}{c}\text { IC card identifying } \\
\text { information }\end{array}$ \\
\hline Certificate information \\
\hline Member ID \\
\hline Login ID \\
\hline Password \\
\hline Accessible flag \\
\hline $\begin{array}{c}\text { Accessible flag updated } \\
\text { time }\end{array}$ \\
\hline $\begin{array}{c}\text { Accessible flag updated } \\
\text { date }\end{array}$ \\
\hline Status accessible flag \\
\hline
\end{tabular}

Figure 3. The illustrative embodiment Filter management table data configuration diagram.

\begin{tabular}{|l|}
\hline member ID hash value \\
\hline $\begin{array}{l}\text { IC card identifying } \\
\text { information }\end{array}$ \\
\hline Certificate information \\
\hline Member ID \\
\hline $\begin{array}{l}\text { member information } \\
\text { was received date }\end{array}$ \\
\hline $\begin{array}{l}\text { member information } \\
\text { was received time }\end{array}$ \\
\hline
\end{tabular}

Figure 4. The gateway part member's data DB data configuration diagram.

\begin{tabular}{|l|}
\hline $\begin{array}{l}\text { IC card identifying } \\
\text { information }\end{array}$ \\
\hline Certificate information \\
\hline Member ID \\
\hline Login ID \\
\hline Password \\
\hline
\end{tabular}

Figure 5. IC card data configuration diagram.

Figure 6 is the illustrative embodiment a gateway management table data configuration diagram.

\begin{tabular}{|c|}
\hline $\begin{array}{c}\text { member ID hash } \\
\text { value }\end{array}$ \\
\hline $\begin{array}{c}\text { member control } \\
\text { information }\end{array}$ \\
\hline $\begin{array}{c}\text { member control } \\
\text { information }\end{array}$ \\
\hline \\
\\
\hline \\
\hline member control \\
information \\
\hline
\end{tabular}

\begin{tabular}{|c|}
\hline Member ID \\
\hline $\begin{array}{c}\text { member information } \\
\text { updated date }\end{array}$ \\
\hline $\begin{array}{c}\text { member information } \\
\text { updated time }\end{array}$ \\
\hline $\begin{array}{c}\text { member information } \\
\text { delivery gateway IP } \\
\text { address }\end{array}$ \\
\hline $\begin{array}{c}\text { member information } \\
\text { delivery gateway IP } \\
\text { address }\end{array}$ \\
\hline $\begin{array}{c}\text { member information } \\
\text { delivery gateway IP } \\
\text { address }\end{array}$ \\
\hline
\end{tabular}

Figure 6. A gateway management table data configuration diagram.

Figure 7 is the illustrative embodiment the center server members' data DB data configuration diagram.

\begin{tabular}{|l|}
\hline member ID hash value \\
\hline $\begin{array}{l}\text { IC card identifying } \\
\text { information }\end{array}$ \\
\hline Certificate information \\
\hline Member ID \\
\hline $\begin{array}{l}\text { member additional } \\
\text { information }\end{array}$ \\
\hline $\begin{array}{l}\text { member information } \\
\text { were received date }\end{array}$ \\
\hline $\begin{array}{l}\text { member information } \\
\text { were received time }\end{array}$ \\
\hline
\end{tabular}

Figure 7. The center server members' data DB data configuration diagram.

Figure 8 is the flow chart which indicates a process of filtering control unit in gateway. filtering control unit receives an access request from client through Network and specific filter. An access request is one of a login request or other data reception. In case of a login request, an access request incidental to IC card information. In case of other data reception, IC card identifying information is added to the head of the data. In a wireless environment, after the access request goes on the directionality analysis to be hereinafter described, change over the filtering control unit 
via the filtering process. Next filtering control unit searches for Filter control table based on IC card identifying information. When there is no IC card identifying information which comes under Filter control table, a record of filter administrative information with relevant IC card identifying information is generated. This record is a blank column outside the field of IC card identifying information.

Next in case of a login request, filtering control unit sets the filter administrative information in which the IC card identifying information relevant. Or Member ID, Login ID and Password are set as Certificate information in relevant filter administrative information respectively. When it isn't a login request, we skip this step. Next refer to accessible flag updated status in relevant filter administrative information. When renewal status of accessible flag updated status isn't renewed, we go to (4) of the member authentication part with relevant filter administrative information of IC card identifying information. And when renewal status of accessible flag updated status is already renewed, we hand to the member authentication part with the IC card identifying information and request to retrieve member management DB. The member authentication part searches for a relevant record, and notifies access control unit of presence or absence of the member information, this content If there is member information. If there is no member information, we go to (6) of the member authentication part. If there is member information, we judge whether relevant filter administrative information accessible flag updated date and accessible flag updated time is newer than member information was received date and member information was received time, or not. If the former isn't newer than the latter, we go to (4) of the member authentication part. If the former is newer than the latter, I go to (5) of the member authentication part.

Figure 9 is the flow chart which indicates a process of the member authentication part in gateway. The member authentication part retrieves for member management DB based on received IC card identifying information. This member information transmission is requested to the Member management part in the Center server over the network. We receive the result and save to the member management $\mathrm{DB}$ in the member authentication part in gateway.

Then present date and time are set as member information was received date and member information was received time.

The member authentication part in gateway monitors accessible flag updated date and Accessible flag updated time from each filter administrative information in Filter control table.

Even if the fixed hour passes, filter gathers dust, we destruct this filter.

Figure 10 is the flow chart indicating a process of the member management part which replies to a members' data transmission request.

Figure 11 is the flow chart indicating a process of the member management part which registrant and renews members' data.

Figure 12 is the flow chart indicating a process of the filtering part. The filtering function part accepts input IC card information through IC card reader or IC card input part. And the Login ID and Password are accepted input from the input device such as the keyboard.

The ratio of the signaling and the noise of the signal vector which is received from $\mathrm{M}$ antennas is maximized in the realm of possibility

$\mathrm{M}$ antennas receive $\mathrm{d}$ the signal vector:

$$
\begin{gathered}
r^{(m)}=A^{(m)} w_{m} S_{m}(t)+A^{(m)} \sum_{k=1, k \neq m}^{K} w_{k S_{k}}(t)+\mathrm{n}^{(\mathrm{m})} \\
r^{(m)}(t)=w_{m}^{H} A^{(m) H} A^{(m)} w_{m} s_{m}(t)+\text { noise }
\end{gathered}
$$

The condition, as follows.:

$$
B^{(m)}=A^{(m) H} A^{(m)}
$$

weighting of media resource control with communicate

$$
w_{m}=e_{\max }^{(m)}
$$

It's restricted by the following condition

The eigenvector which maximizes the agential value of

$$
e_{\max }^{(m)}: B^{(m)}
$$

Figure 13 is the transition diagram of the indication screen with filtering function part procedure.

As observed above, in one embodiment when the member authentication performed by an application layer is NG, we make relevant filter which belongs to a physical layer become extinct.

Figure 14 is the illustrative embodiment network access management system configuration diagram in the wireless environment.

The contents which are being described to Figure 14 from Figure 2 become possible by solution of high accuracy executing the algorithm which is proposed in this paper, and Network access control technique using filtering technology which can specify the channel where data is sent. This filtering technology is expressed in Figure 27 from Figure 23.

Figure 15 is the explanatory diagram which explains radio aim and a method of an electric power density distribution of receiving side and a directivity analysis. The arrival corner distribution causes an arrival radio wave as well as radio arrival delay forms, so when an arrival corner - time plane is taken for a xy plane, the electric power density can be the price of the $\mathrm{z}$ axial direction and indicate the distribution by a contour line.

Figure 16 is the data configuration diagram which indicates the illustrative embodiment received signal control table.

Figure 17 is the data configuration diagram which indicates the directivity analysis result control table. 


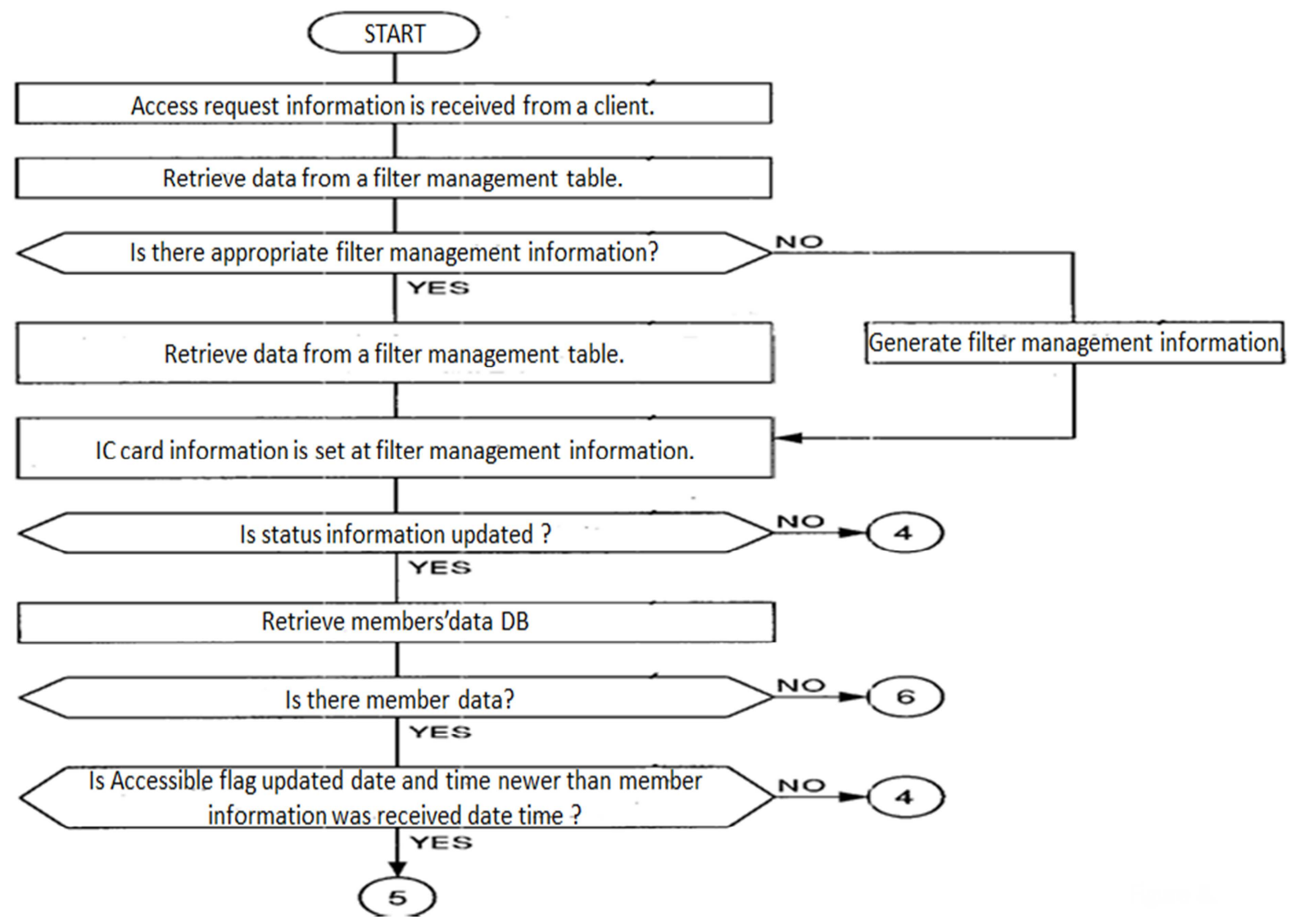

Figure 8. A process of the illustrative embodiment filtering control unit.

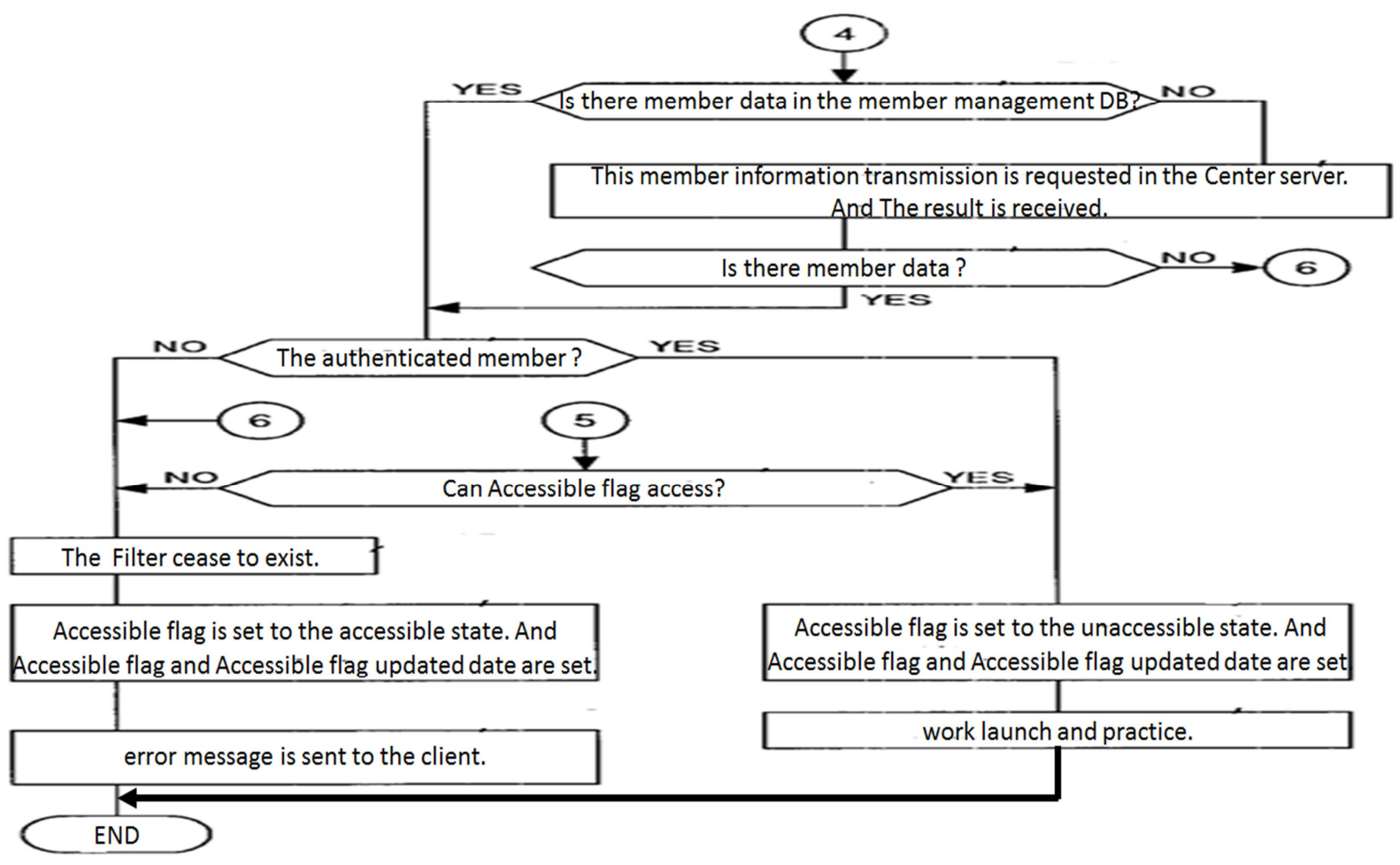

Figure 9. The flow chart indicates a process of the member authentication part. 


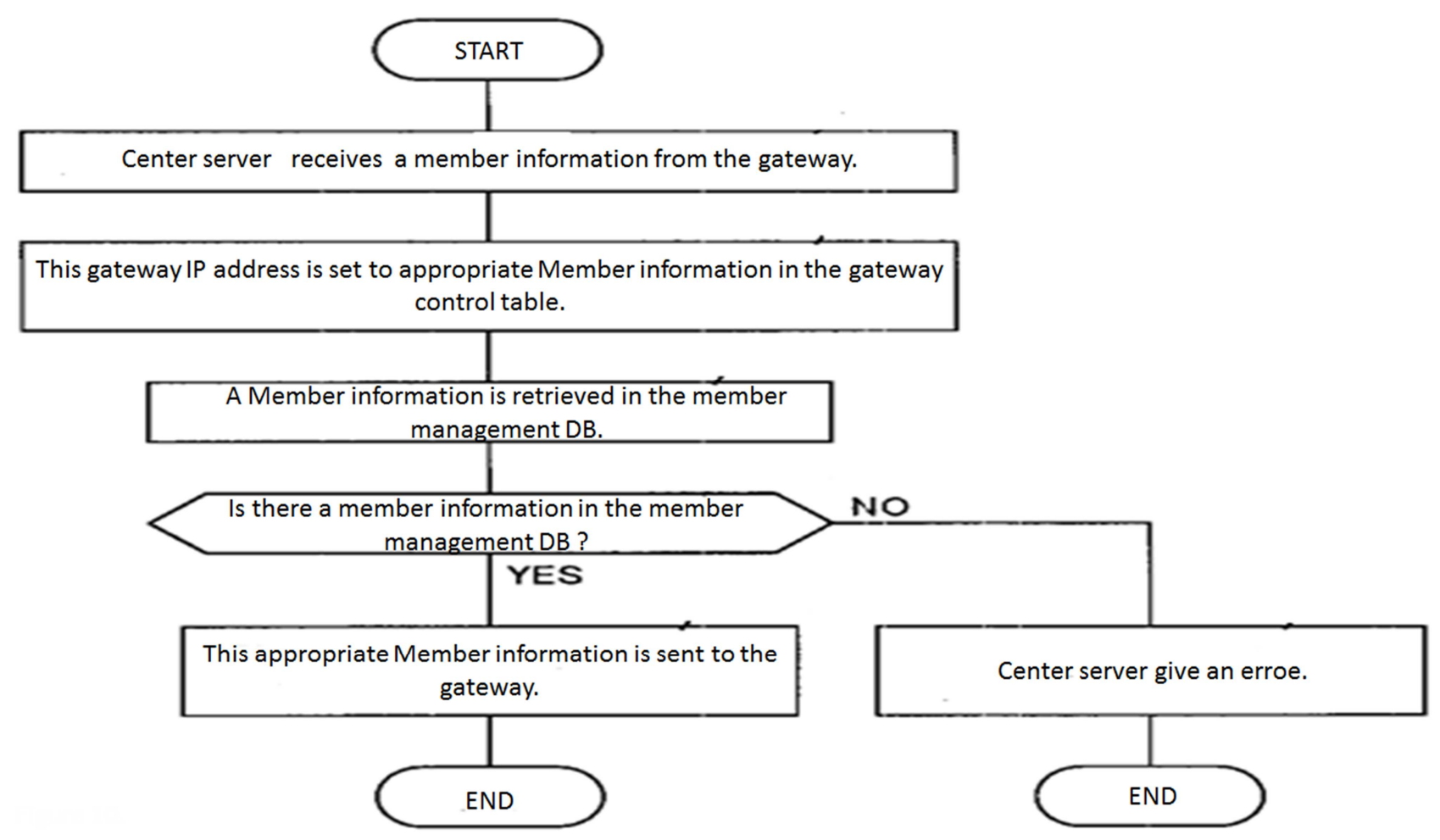

Figure 10. The flow chart indicates a process of the member management part which replies to a members'data transmission request.

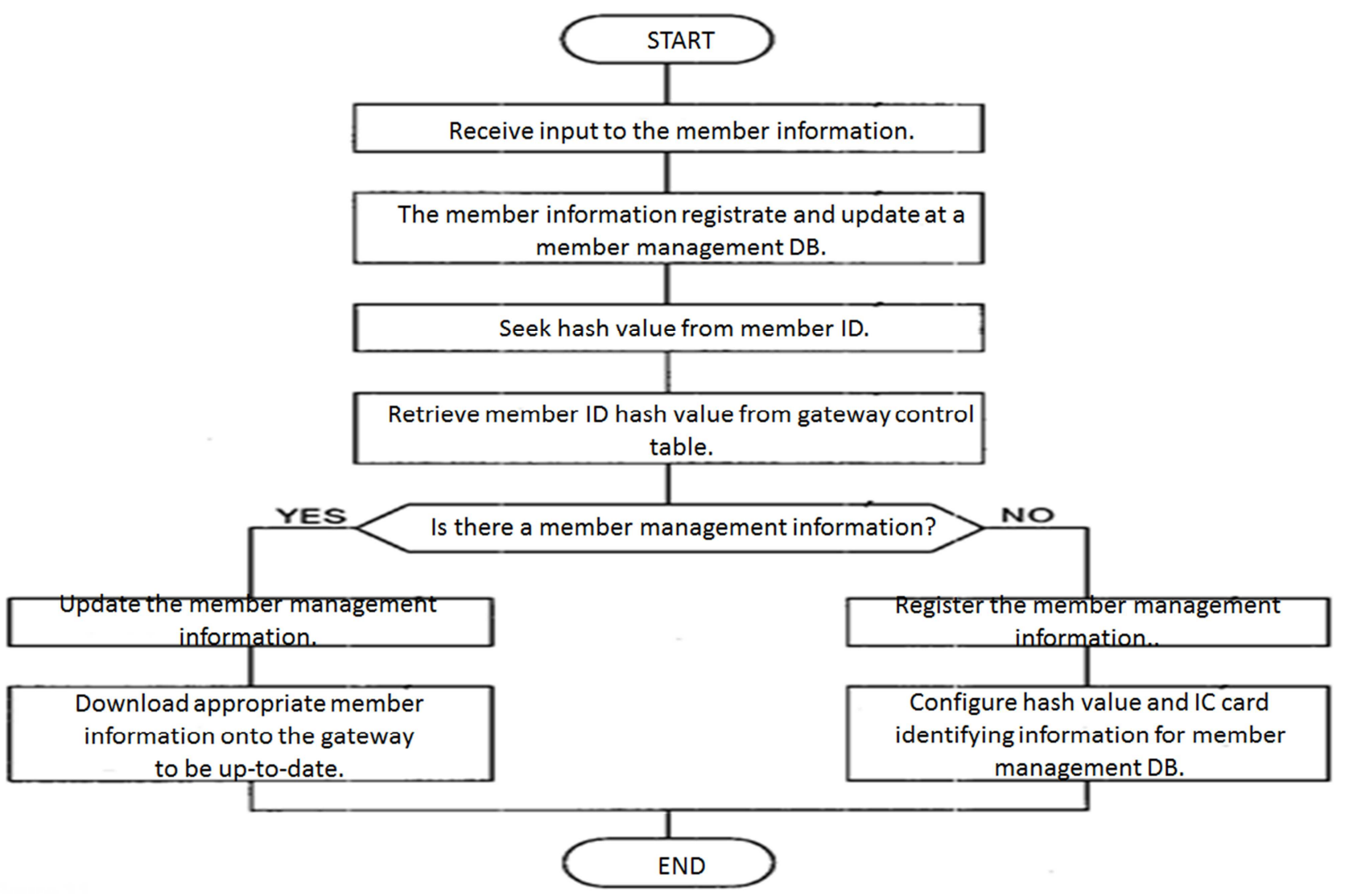

Figure 11. The flow chart indicating a process of the member management part which registrant and renews members'data. 


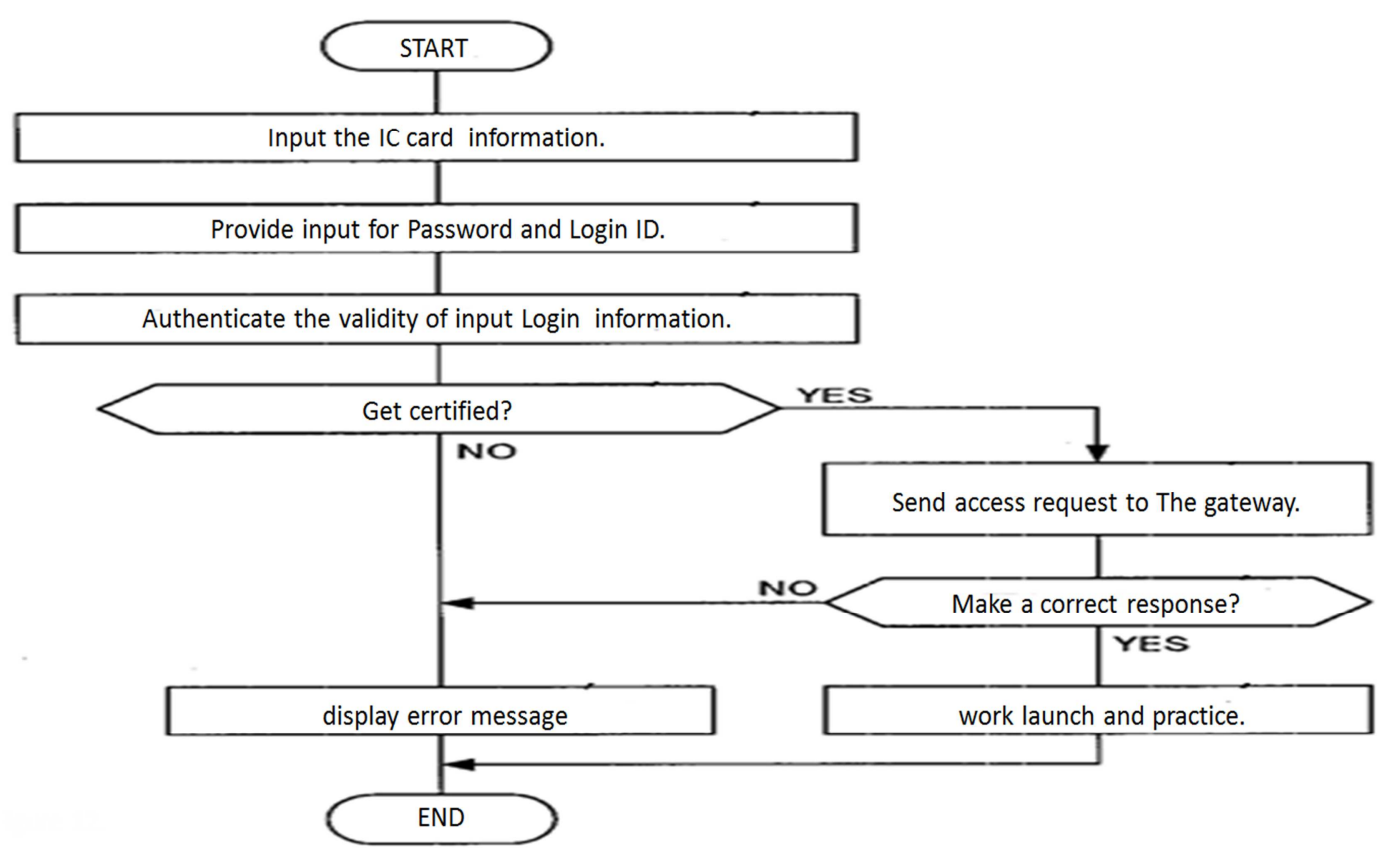

Figure 12. The flow chart indicates a process of the filtering part.

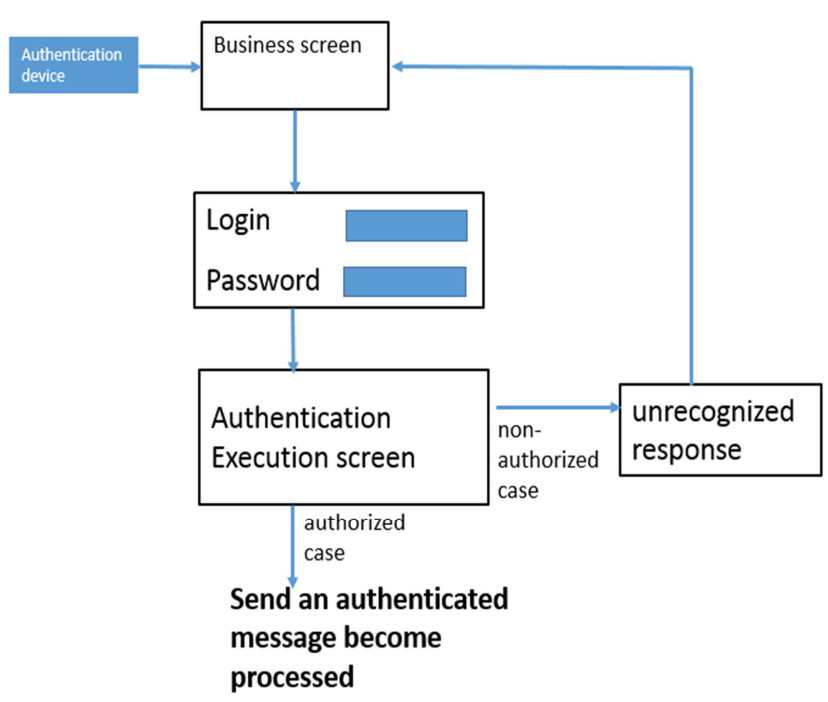

Figure 13. The transition diagram of the indication screen with filtering function part procedure.

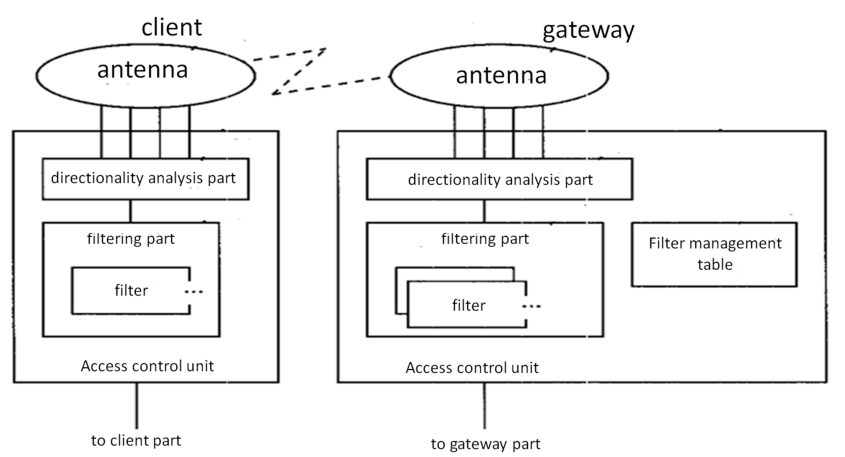

Figure 14. Network access management system configuration diagram in the wireless environment.

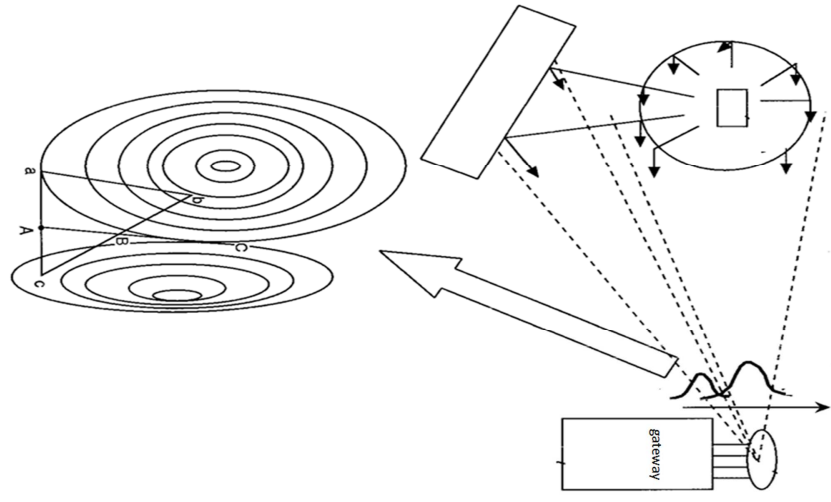

Figure 15. The explanatory diagram which explains radio aim and a method of an electric power density distribution of receiving side and a directivity analysis.

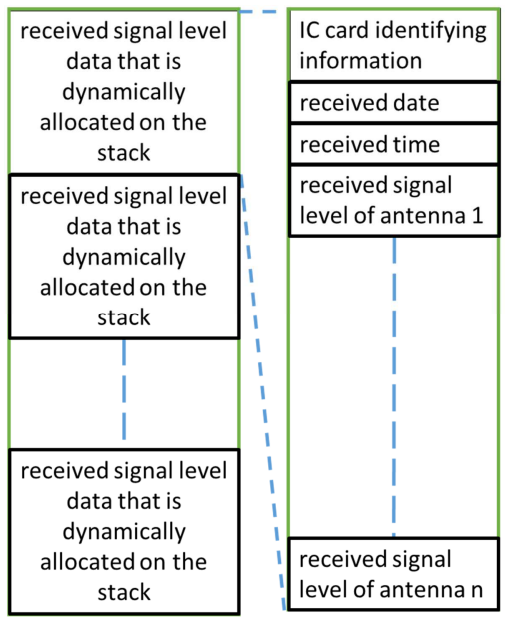

Figure 16. The data configuration diagram which indicates the illustrative embodiment received signal control table. 


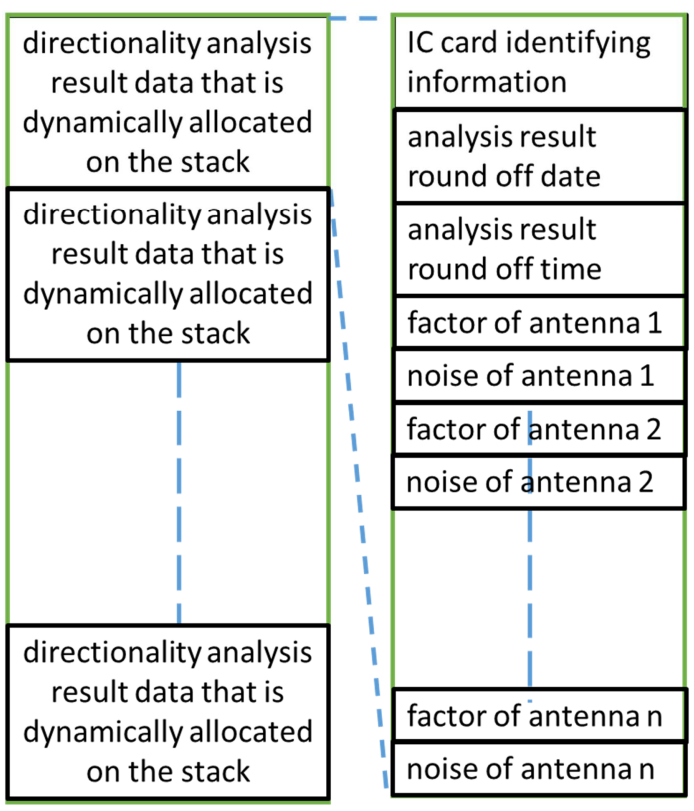

Figure 17. The data configuration diagram which indicates the directivity analysis result control table.

\begin{tabular}{|l|}
\hline $\begin{array}{l}\text { IC card identifying } \\
\text { information }\end{array}$ \\
\hline received date \\
\hline received time \\
\hline sequence number $\mathrm{nn}$ \\
\hline $\begin{array}{l}\text { constrained condition } \\
\text { parameter }\end{array}$ \\
\hline
\end{tabular}

Figure 18. The data configuration diagram which indicates the committed constraint condition to memory control table.

Figure 18 is the data configuration diagram which indicates the committed constraint condition to memory control table.

To Figure 22 from Figure 19 are the flow chart which expresses the flow of processing of directionality analysis part.

Figure 19 is the flow chart expressing a process of the illustrative embodiment directivity analysis part. (1/4)

Figure 20 is the flow chart expressing a process of the illustrative embodiment directivity analysis part. (2/4)

Figure 21 is the flow chart expressing a process of the illustrative embodiment directivity analysis part. (3/4)

Figure 22 is the flow chart expressing a process of the illustrative embodiment directivity analysis part. (4/4)

A each antenna of the MIMO channel resource control media receiving weight determine as high as reasonably achievable the signaling-the noise ratio of the signal vector which is received by a MIMO channel When this expression also replace each antenna with each communication channel, it can be used as the expression to decide about the strength of the transmission bit which sort into different communication channel.
(1) Summary of the method

We propose the advanced constrained simplex method. What solves problem within constrained condition, and it does not depend on the figure of object function or initial point.

The equality constrained nonlinear programming problem is

Minimize $f(x)$

Subject to

$$
\text { gi }(x)=1, j=1, m
$$

Where $\mathrm{x}=(\mathrm{x} 1, \mathrm{xn}) \mathrm{T}, \mathrm{n}>\mathrm{m}$, and both $\mathrm{f}(\mathrm{x})$ and gi $(\mathrm{x})$ are

Assumed to have continuous second partial derivatives.

Step 1) we decide a first point, which can be satisfied constraint function.

Step 2) Decide $n$ points which is produced by random function.

Step 3) if $m(m=<n)$ the value is not sufficient constraint function, 1 through to the $(m-1)$ the point of middle point $m$ the point moves half distance

to the middle point of the 1 through to the $(m-1)$ the point.

Step 4) above $n+1$ points are estimated by object function.

Step 5) the point $A$ is the middle point of the $n$ points without the best value point. The point $\mathrm{B}$ is the middle point of the $\mathrm{n}$ points without the worst value point.

Step 6) There is the point $C$ at the opposite side of point $A$ with point $\mathrm{B}$. And point $\mathrm{C}$ to point $\mathrm{B}$ is 2 times longer than point $A$ to point $B$.

Step 7) if point $C$ is not satisfied constrains function; next point $C$ is middle of point $C$ and $B$. If point $C$ is not satisfied until distance of point $\mathrm{C}$ and point $\mathrm{B}$ is less than 0.000001, point $B$ is point $C$.

Step 8) a method that has been the subject of much recent research for the solution of (1) is the sequential quadratic programming (SQP) technique.

A current estimate $x^{(k)}$ to the minimized $x^{*}$ is known, and a search direction $s^{(c)}$ is generated to solve the quadratic programming problem

$$
\text { Minimize } \frac{1}{2} S^{(k) T} B^{(k)} S^{(k)}+S^{(k) T} \nabla f\left(x^{(k)}\right)
$$

Subject to

$$
\nabla g\left(x^{(k)}\right)^{\tau} S^{(k)}+g\left(x^{(k)}\right)=0,
$$

Where

$$
\nabla g\left(x^{(k)}\right)=\left\{\nabla g_{1}\left(x^{(k)}\right), \cdots, \nabla g_{m}\left(x^{(k)}\right)\right\},
$$

the matrix of the constraint normal evaluated at $x^{(k)}, g^{(k)}$ is the vector $\left(g_{1}(x), \cdots, g_{m}(x)\right)^{T}$, and $B^{(k)}$ is a positive definite approximation to the Hessian of the Lagrange with respect to $\mathrm{x}$. Here the Lagrange is

$$
l(x, \lambda)=f(x)-\lambda^{\mathrm{T}} g(x),
$$


Where $\lambda=\left(\lambda_{1}\right.$, $\left.\lambda_{m}\right)^{\mathrm{T}}$ is the vector of Lagrange estimate $\lambda^{(k)}$ to the optimal Lagrange multipliers $\lambda^{*}$. multipliers, and $B^{(k)}$ is an estimate to $l_{x x}\left(x^{(k)}, \lambda^{(k)}\right)$ for an

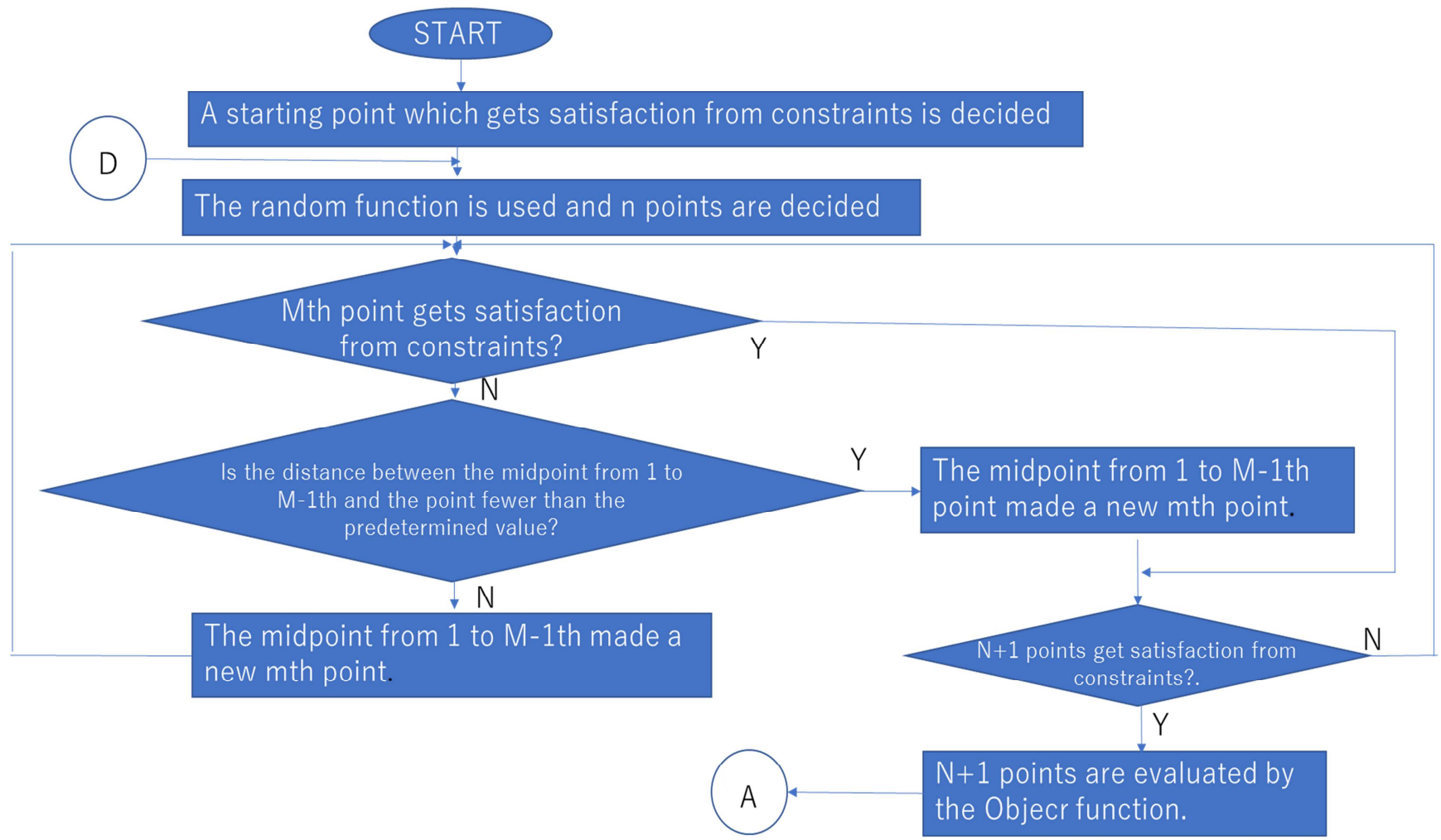

Figure 19. The flow chart indicates a process of the illustrative embodiment directivity analysis part. (1/4).

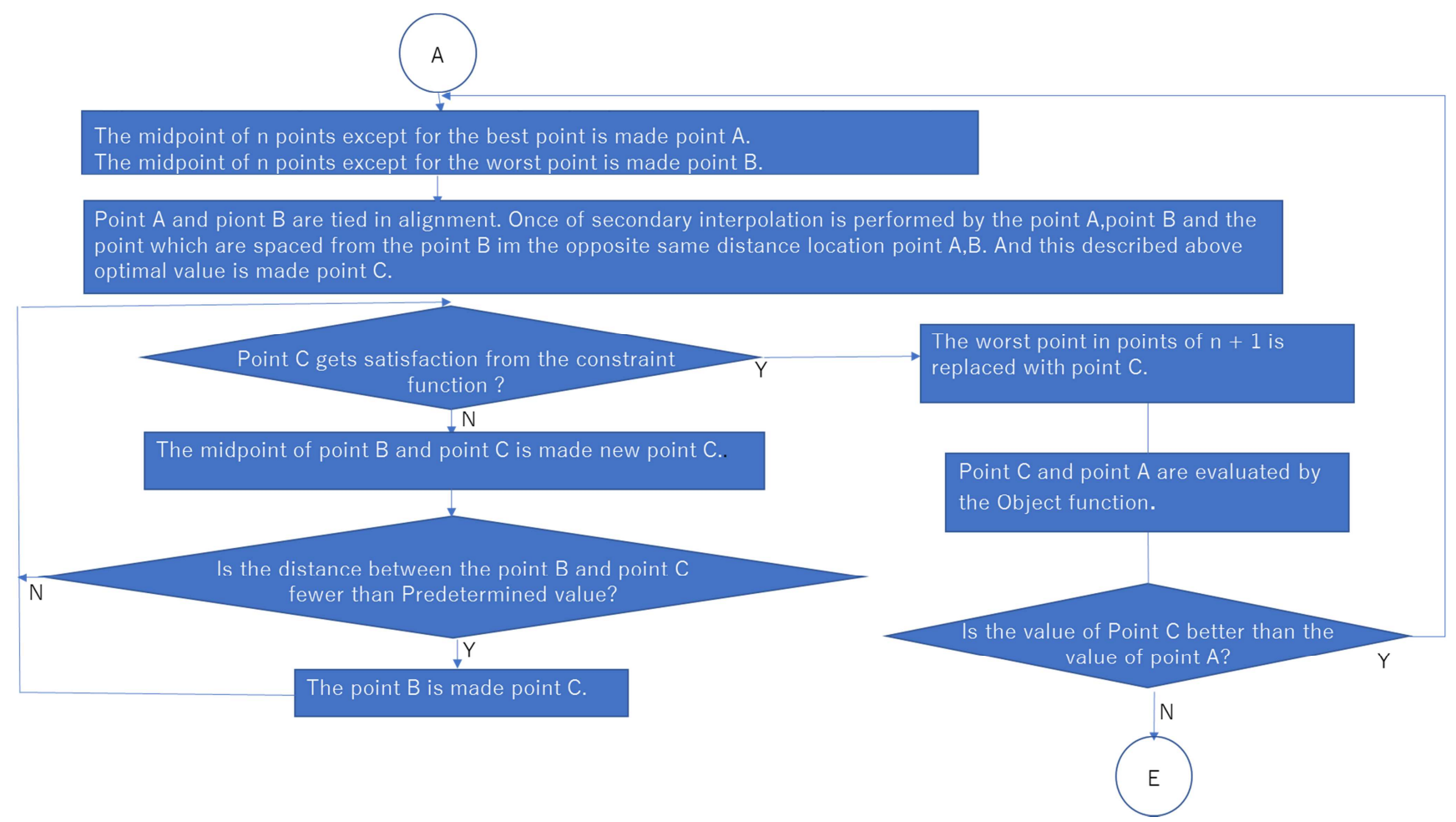

Figure 20. The flow chart indicates a process of the illustrative embodiment directivity analysis part. (2/4). 


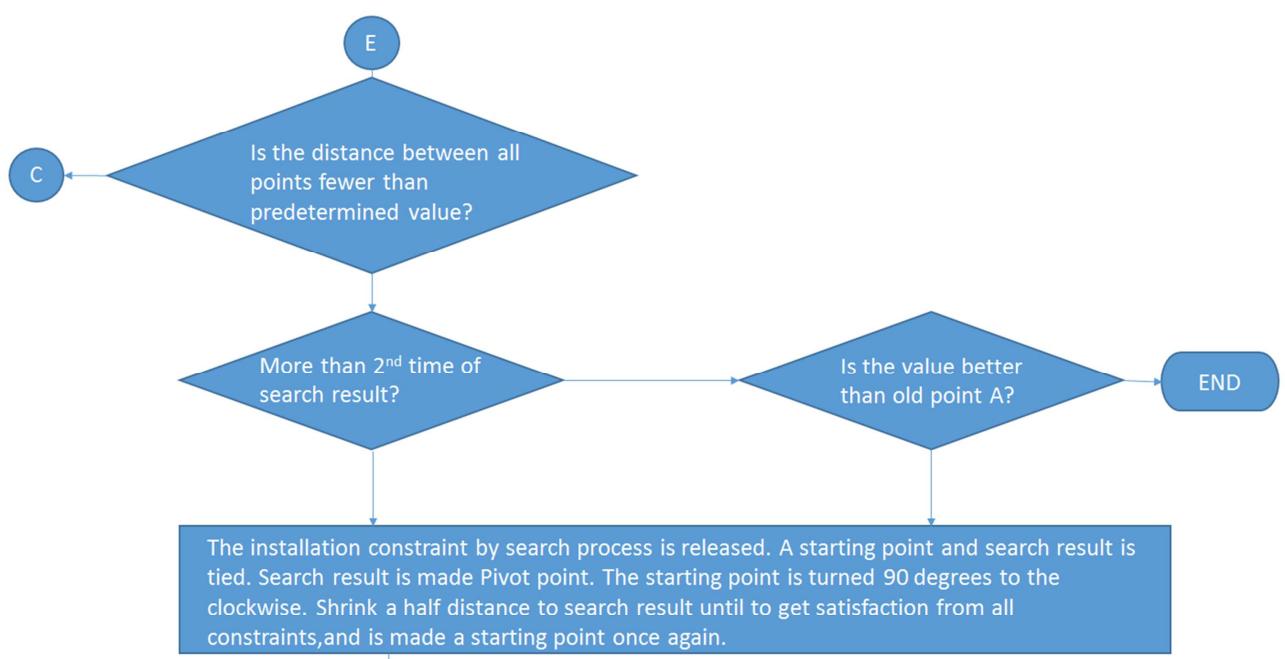

D

Figure 21. The flow chart indicates a process of the illustrative embodiment directivity analysis part. (3/4).

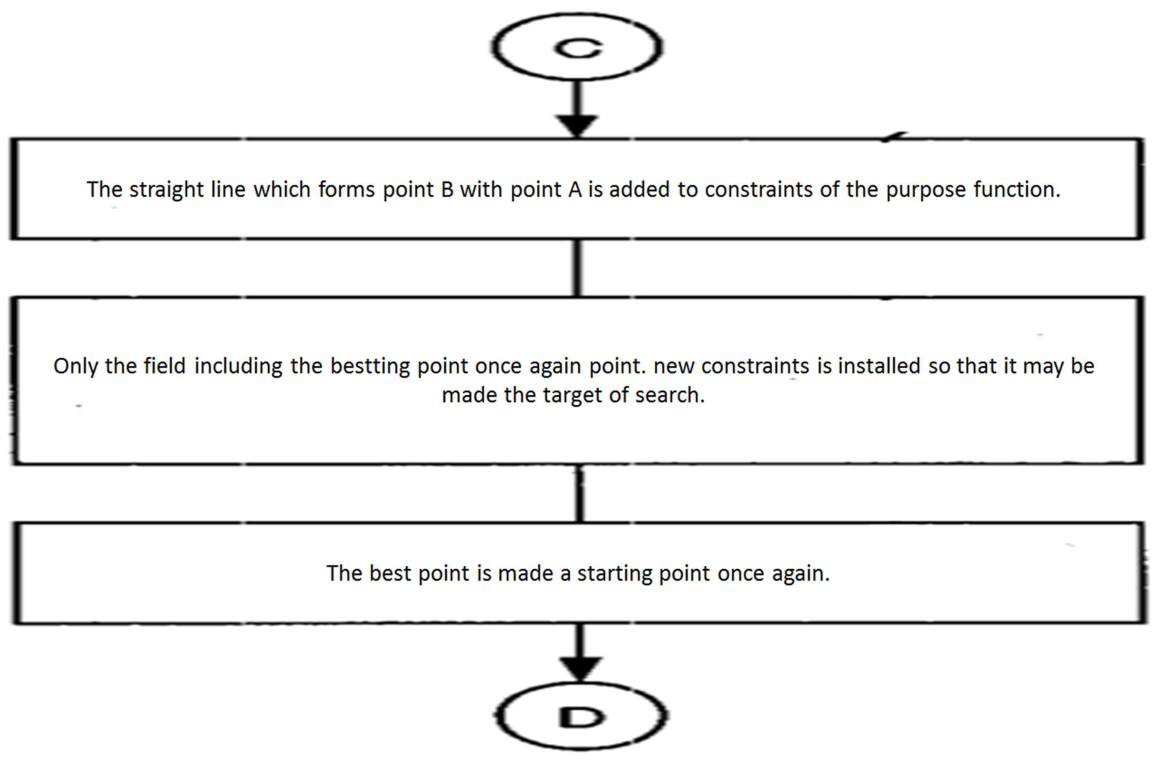

Figure 22. The flow chart expresses a process of the illustrative embodiment directivity analysis part (4/4).

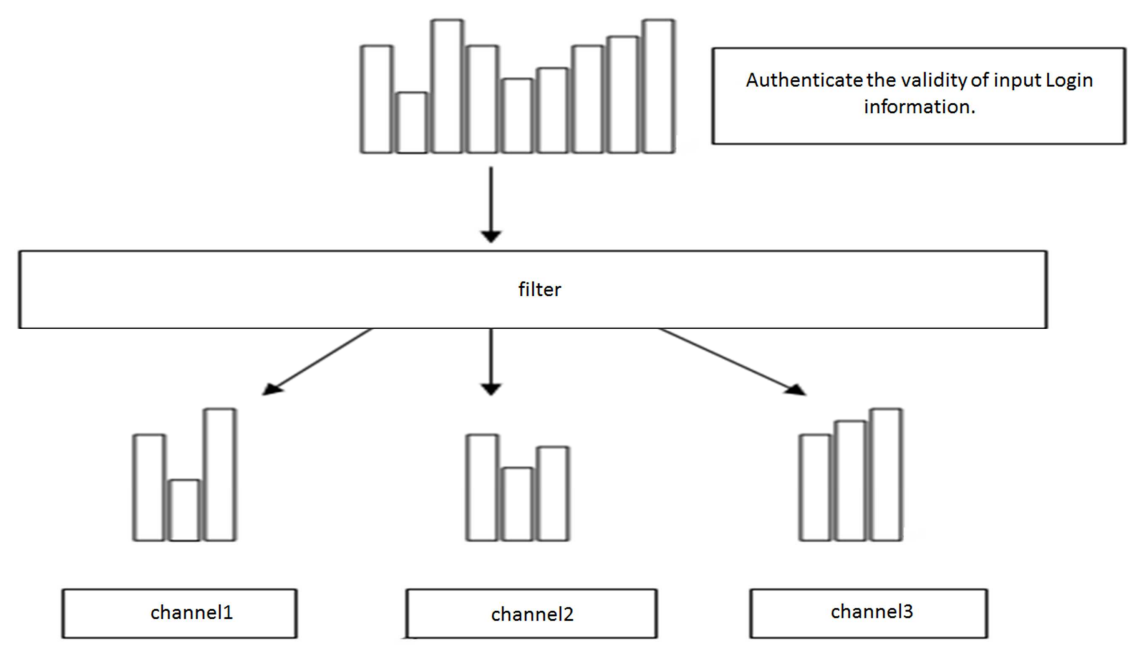

Figure 23. The figure of a multiplied data block which passes filter equipment apart and broke down into a network of the different channels. 
Step 9) in step 8, we find a new point. And this point is estimated object function. If this new point is not good more than old $\mathrm{C}$ point, and $\mathrm{n}+1$ points are not within 0.000001 , then we add to new constraint function that it is point $\mathrm{B}$ to point $\mathrm{C}$ line function. And now the best point is decided original point. Go to step 2. If this new point is good more than old $\mathrm{C}$ point, then this new point is new $\mathrm{C}$ point. Go to step 5. If this new point is not good more than old $\mathrm{C}$ point, and $\mathrm{n}+1$ points are within 0.000001 , then this research has finished. We continue the iterative procedure a new estimate to the minimized.

Figure 23 is the figure of a multiplied data block which passes filter equipment apart and broke down into a network of the different channels.

\section{Evaluation}

We evaluate three cases on the simulation.

Case 1;

Object function and constraint function are normal. And the existing method can solve that.

Case 2;

There are two object functions in the research field. In this case, the complex method cannot solve this problem.

The advanced constrained simplex method, can solve this problem.

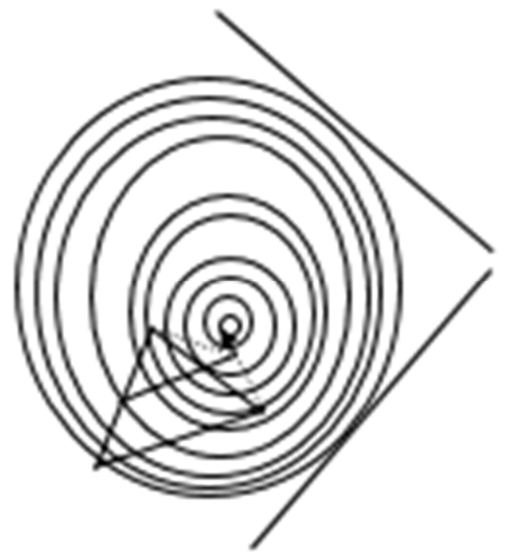

Figure 24. The processing of case $1(1 / 3)$.

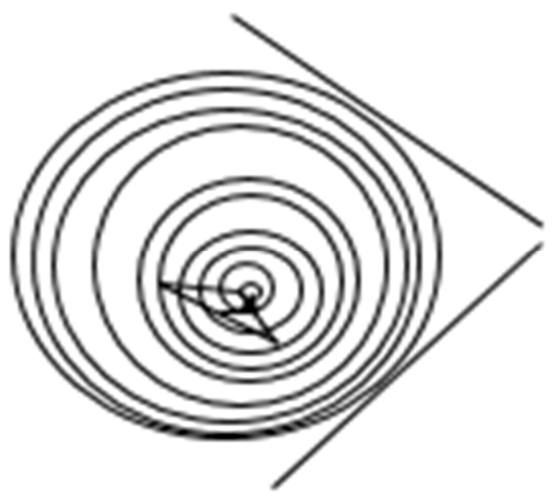

Figure 25. The processing of case 1 (2/3).

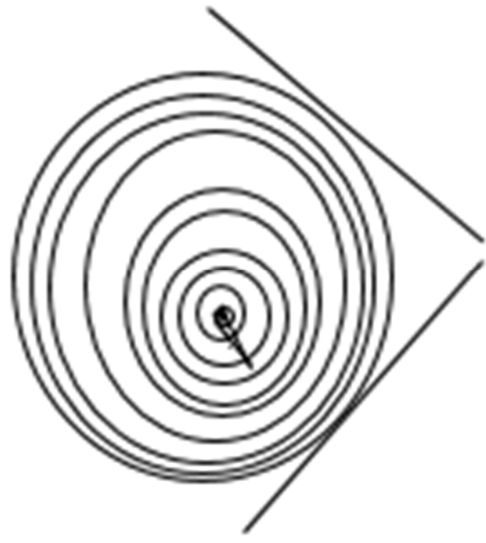

Figure 26. The processing of case 1 (3/3).

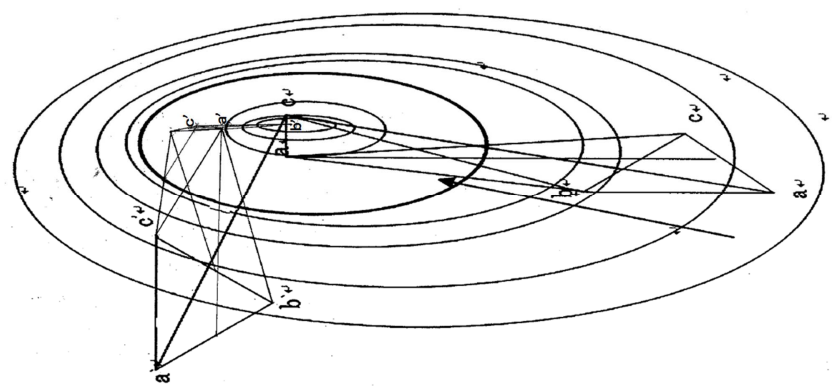

Figure 27. Twice of search result.

Table 1. Compare calculation times with the classical simplex method and this complex method.

\begin{tabular}{lll}
\hline & Case 1 & Case 2 \\
\hline the classical simplex method [24] & 36 & - \\
This complex method & 20 & 75 \\
\hline
\end{tabular}

Figure 27 is described the following. The starting point after getting an analysis result once, which ties the first starting point a and point $\mathrm{C}$ of the value of the analysis result, and makes them revolve around first starting point a clockwise 90 times centering on point $\mathrm{C}$ of the value of the analysis result, and is the 2nd time, the figure which is being analyzed once again as point a.

Security is one of the key technologies with which DX (Digital Transformation) supported. Service of a block chain requires robust Secure network. Not security service at conventional one dimension and two dimensions, but the space which is security is requested of a block-chain technology.

\section{Conclusions}

In this paper, we proposed MIMO systems in Network access management technology using filtering technique.

This paper has three main contributions. First, we can confirm networking factor of Network access management technology using filtering technique for MIMO systems. Second, we describe advanced constrained simplex method. Finally, advanced constrained simplex method is described how to resolve the problem of the multiple-input multiple-out. 
When A MIMO system calculates the weight of each antenna, we cluster about the strength of the radio wave in the radio reception territory and next search optimum solution in clustering. Therefore, to need much calculated amount, when getting weight of the correct most suitable antenna, the feature of the MIMO system couldn't be utilized. This proposed method is searching for the optimum solution while clustering This can achieve more compact than the conventional Quantum network environment.

Therefore, this advanced constrained simplex method can reduce calculated amount, when getting weight of the correct most suitable antenna, the feature of the MIMO system in Network access management technology using filtering technique could be utilized. And, the algorithm proposed this time achieves network access management using filtering technique by demanding the most optimum value of expression.

\section{Acknowledgements}

The author would like to thank Hitachi, Ltd. for technical support. In particular, patent number JP4750828.

\section{References}

[1] Han, S. P. Superlinearly convergent variable metric algorithms for general nonlinear programming problems. $\mathrm{M}$.

[2] Powell, M. J. D. Algorithms for nonlinear constraints that use Lagrangian functions. Math, Program. 14 (Mar, 1978), 224-248.

[3] Powell, M. J. D. The performance of two subroutines for constrained optimization on some difficult test problems. In Numerical Optimization 1984. P. T. Boggs, R. H. Byrd, and R. B. Schnabel, Eds. SIAM, Philadelphia, 1985, 160-177.

[4] Powell, M. J. D., and Yuan, Y. A recursive quadratic programming algorithm that uses differentiable exact penalty functions. Math, Program. 35 (July 1986), 265-278.Chamberlain, R. M., Lemarechal, C., Pedersen, H. C., and Powell, M. J. D. The watchdog technique for forcing convergence in algorithms for constrained optimization. Math, Program. Stud. 16 (Mar. 1982), 1-17.

[5] Mar. 1982 Chamberlain, R. M., Lemarechal, C., Pedersen, H. C., and Powell, M. J. D. The watchdog technique for forcing convergence in algorithms for constrained optimization. Math, Program. Stud. 16 (Mar. 1982), 1-17.

[6] SIAM Powell, M. J. D. The performance of two subroutines for constrained optimization on some difficult test problems. In Numerical Optimization 1984. P. T. Boggs, R. H. Byrd, and R. B. Schnabel, Eds. SIAM, Philadelphia, 1985, 160-177.

[7] Tapia, R. A. Diagonalized multiplier methods and quasi-Newton methods for constrained optimization. J. Optim. Theor. Appl. 22 (June 1977), 135-184.

[8] Celis, M. R., Dennis, J. E., and Tapia, R. A. A trust region strategy for nonlinear equality constrained optimization. In Numerical Optimization, 1984. P. T. Boggs, R. H. Byrd, and R. B. schnabel, Eds. SIAM, Philadelphia, 1985, 71-82.
[9] Tapia, R. A. Quasi-Newton method for equality constraint optimization: Equivalence of existing methods and a new implementation. Nonlinear Programming 3. O. L. Mangasarian, R. R. Meyer, and S. M. Robinson, Eds. Academic Press, New York, 1978, 125-164.

[10] SIAM Celis, M. R., Dennis, J. E., and Tapia, R. A. A trust region strategy for nonlinear equality constrained optimization. In Numerical Optimization, 1984. P. T. Boggs, R. H. Byrd, and R. B. schnabel, Eds. SIAM, Philadelphia, 1985, 71-82.

[11] Boggs, P. T., and Tolle, J. W. A family of descent functions for constrained optimization. SIAM J. Number. Anal. 21 (Dec. 1984), 1146-1161.

[12] Boggs, P. T., and Tolle, J. W. A strategy for global convergence in a sequential quadratic programming algorithm. To appear in SIAM J. Number. Anal. 21 (Dec. 1984), 1146-1161.

[13] SIAM J. Coleman, T., and Conn, A. On the local convergence of a quasi-Newton method for the nonlinear programming problem. SIAM J. Numer. Anal. 21 (Aug. 1984), 755-769.

[14] Di Dillo, G., and Grippo, L. A new class of augmented Lagrangians in nonlinear programming. SIAM J. Control Opt. 17 (Sept. 1979), 618-628.

[15] Fontecilla, R. A general convergence theory for quasi-Newton methods for constrained optimization. Ph.D. dissertation, Mathematical Sciences Dept., Rice Univ., Houston, Tex., 1983.

[16] Glad, S. T. Properties of updating methods for the multiplies in augmented Lagrangiahs. J. Optim. Theor. Appl. 28 (June 1979), 135-156.

[17] Nocedal, J., and Overton, M. Projected Hessian updating algorithms for nonlinearly constrained optimization. To appear inSIAM J. Numer. Anal.

[18] Schittkowski, K. The nonlinear programming method of Wilson, Han, and Powell with an augmented Lagrangian type line search function, Part I: Convergence analysis. Numer. Math 38, 1 (1981), 83-114.

[19] Rice Univ Fontecilla, R. A general convergence theory for quasi-Newton methods for constrained optimization. Ph.D. dissertation, Mathematical Sciences Dept., Rice Univ., Houston, Tex., 1983.

[20] Numer. Math 38 Schittkowski, K. The nonlinear programming method of Wilson, Han, and Powell with an augmented Lagrangian type line search function, Part I: Convergence analysis. Numer. Math 38, 1 (1981), 83-114.

[21] Tomonobu, S., Modeling and Simulation in Wireless Sensor Networks, Journal of Wireless Communications (JOWC) Special Issue on Wireless Sensor Networks - Special Issue on Wireless Sensor Networks, July, 2017

[22] MIT Press, Cambridge I Nemenman, F Shafee \&WBialek, in Advances in Neural Information Processing 14, TG Dietterich, S Becker \& Z Ghahramani, eds, pp 471-478 (MIT Press, Cambridge, 2002).

[23] N. Slonim, G. S. Atwal, G. Tkacik, W. Bialek, "Estimating Mutual Information and Multi-Information in Large Networks," http://arxiv.org/abs/cs/0502017.

[24] BOX, M. J. A New method of constrained optimization and a comparison with other methods. Computer J. 8 (1965), 42-52. 